\title{
Knowledge, Attitudes and Practices on Malaria Prevention and Control Among Private Security Guards Within Kaduna Metropolis, Kaduna State-Nigeria
}

\author{
Victor Oluwasanmi Amusan*, Yahaya Abdullahi Umar, Philip Anthony Vantsawa
}

Department of Biological Sciences, Nigerian Defence Academy, Kaduna, Nigeria

Email address:

voaplus@yahoo.com (V. O. Amusan)

${ }^{*}$ Corresponding author

To cite this article:

Victor Oluwasanmi Amusan, Yahaya Abdullahi Umar, Philip Anthony Vantsawa. Knowledge, Attitudes and Practices on Malaria Prevention and Control Among Private Security Guards Within Kaduna Metropolis, Kaduna State-Nigeria. Science Journal of Public Health.

Vol. 5, No. 3, 2017, pp. 240-245. doi: 10.11648/j.sjph.20170503.22

Received: February 19, 2017; Accepted: March 26, 2017; Published: March 31, 2017

\begin{abstract}
An understanding of knowledge, attitudes and practices among different populations such as security guards temporarily outside the home due to occupational reasons are key determinants for policy makers in designing malaria prevention and control interventions. A survey on knowledge, attitudes and practices (KAP) on malaria prevention and control was conducted among two hundred and sixty-one (261) private security guards in Kaduna Metropolis, Kaduna State-Nigeria using a structured questionnaire. Data were analysed using SPSS version 20 while associations between variables were tested using a Chi-Square test with the level of statistical significance set at 5\%. There were $253(96.94 \%)$ respondents with a high knowledge score about malaria, $201(78 \%)$ of respondents with a positive attitude and there were $192(74 \%)$ of respondents with good malaria practices score. The majority $(97.7 \%)$ of the respondents have heard about malaria before while $96.9 \%$ of respondents correctly associated mosquito as malaria vector. The radio serves the majority $(93.1 \%)$ as their source of information about malaria. Wearing long-sleeved shirts, trimming of bushes and use of ITNs are the leading malaria prevention methods practised by the respondents. Statistically significant association between malaria practice scores and respondent's age $(p$-value $=0.022)$, gender $(p-v a l u e=0.002)$ and level of education $(p$-value $=0.006)$ was reported. Respondent's knowledge about malaria $(\mathrm{p}=0.008)$ and attitude towards malaria $(\mathrm{p}=0.020)$ were found to significantly influence their practices towards malaria. For sustainable implementation of malaria intervention programmes, good malaria practices in conjunction with high level of awareness by the respondents are quite significant. One of the methods for malaria control that leads to morbidity and mortality reduction is educational based teachings on understanding individual knowledge, attitudes and practices on malaria.
\end{abstract}

Keywords: Knowledge, Attitudes, Practices, Malaria, Guards

\section{Introduction}

Malaria is the most common protozoan parasitic disease in the tropical and subtropical regions of the world and is transmitted to man through the bites of infected female anopheline mosquito [1, 2]. The vector borne parasitic infection is caused by Plasmodium species namely Plasmodium falciparum, $P$. ovale, $P$. vivax, and $P$. malariae [3]. However, infections due to $P$. falciparum is the most common and deadly [4].

Malaria is a major public health problem in 97 countries and territories in the tropics and subtropics. Globally, nearly
214 million cases of malaria occur annually with about 3.2 billion people at risk of infection [5]. Approximately 438,000 deaths were attributed to malaria in 2015 , particularly in subSaharan Africa, where an estimated $90 \%$ of all malaria deaths occur [5].

Nigeria is a high endemic country for malaria but tremendous gains have been made in the fight against malaria in the past few years. Notwithstanding, the disease still remains a major health challenge in Nigeria with high morbidity and mortality which has enormous consequences on the economy. The etiology of the disease which is the sum total of all the factors contributing to the occurrence of the 
disease depends on the interaction of the agent, the host, and the environment which determines whether or not a disease develops. The contribution of the host has a distinct role in the transmission process, based on its capacity to affect the reservoir base of parasites $[6,7]$.

The scope of malaria control is changing worldwide with emphases placed on community and individual participation in malaria control and prevention measures rather than exclusive use of insecticides leading to the rapid rise of health education based on understanding knowledge, attitudes and practices (KAP) towards malaria control $[8,9]$. Novel reports about knowledge, attitudes, and practices relating to malaria and its control are not lacking but these reports concluded that misconceptions on malaria transmission and risk factors still exist with negative impact on malaria control programmes [10-14].

Extensive public health promotional programs which focus on modern and established methods of malaria prevention and management is needed to achieve sustainable control of the disease. The importance of human behaviour in malaria transmission has not been extensively evaluated even though much is known about vector biology. Malaria control programmes must therefore consider the broad, complex and interrelated factors that influence human behaviour. The importance of information on KAPs in designing and improving malaria control activities has been emphasised [8]. Studies on KAP are also essential in establishing epidemiological and behavioural baselines useful to identify indicators for monitoring malaria control programmes.

Private security guards consisting of abled men and women are usually trained to provide day and night watch over private and public properties such as companies, banks, schools, hospitals and homes. These guards are exposed to vector borne diseases such as malaria due to the fact that many at times they spent the night on duty. Documented information on the KAPs associated with malaria transmission among different populations such as security guards temporarily outside the home due to occupational and recreational reasons in Kaduna State like many other States in Nigeria is lacking.

This study is aimed at assessing the KAP on malaria prevention and control among private security guards within Kaduna metropolis, Kaduna State-Nigeria. The outcome of this study will contribute towards designing basic, effective and sustainable malaria control strategies.

\section{Materials and Methods}

\subsection{Study Area}

Kaduna metropolis is the capital of Kaduna State and is located in the North-West geopolitical zone of Nigeria. It lies between latitude $10^{\circ} 20^{\prime} \mathrm{N}$ and $10.33^{\circ} \mathrm{N}$, and longitude $7^{\circ} 45^{\prime}$ $\mathrm{E}$ and $7.75^{\circ} \mathrm{E}$. The state shares borders with Kano, Katsina and Zamfara states to the North, Plateau and Bauchi states to the East, Nasarawa state and the Federal Capital Territory (FCT) to the South and Niger state to the West [15]. Kaduna
State have distinct dry and wet seasons and is characterised by Guinea savannah type of vegetation [16].

\subsection{Study Population/Sample Size}

The study population was made up of 234 male and 27 female private security guards keeping watch on private and public properties in Kaduna Metropolis, Nigeria. The study population consists of guards who have voluntarily consented to participate in the study.

\subsection{Ethical Permission}

The study protocol was approved by Kaduna State Ministry of Health Ethical Committee before data collection commenced among the security guards. The aim of the study was also clearly explained to the guards in order to get their informed consent while guards who do not consent were excluded from the study. The security guards were also reminded of their right to decline to take part in the study as well as to withdraw any time during the interview. Confidentiality was assured and maintained throughout the study. Code of ethics on the use of human subjects in research as outlined in the NDA Research and Development Policy, 2016 was also adhered strictly.

\subsection{Questionnaire Administration}

Well-structured questionnaire was administered to obtain information that sought to gain insight into the guard's knowledge, attitudes and practices (KAP) towards malaria. It also covered demographic characteristics of respondents as well as bed net ownership and use, sources of information about malaria and treatment seeking behaviours. Each questionnaire was assigned a code to enable tracking of respondents. The questionnaire was interpreted in local language for those who do not understand English. This study used similar principles to generate multiple-choice questions, each of which was scored one point for a correct response and zero for the rest. An overall knowledge score was calculated by adding up the scores for each respondent across the scaled questions. Respondents answered a combination of positive and negative statements to help gauge their attitude towards malaria using a 3-point scale ranging from - Yes (score 3) to I don't know (score 1). The questions that indicated malaria practices were scored for each respondent. If a respondent indicated that they -"always" performed a good practice i.e. sleeping under a mosquito net, they were given a score of two points. If they indicated that they - "sometimes" performed a good practice, they were given a score of one point. If on the other hand, they indicated they - "never" performed a good practice, they were given a score of zero. An overall practices score was determined for each respondent by adding up the scores across the malaria practices questions [13].

\subsection{Statistical Analysis}

Data collected was processed using EpiData version 3.1 and each dataset subsequently exported to SPSS version 20 
for analysis. Datasets were analysed and interpreted using descriptive statistics. Chi-Square test was used to test association between variables. Five $(5 \%)$ level of probability was considered significant $(\mathrm{p}<0.05)$.

\section{Results}

\subsection{Demographic Characteristics of the Respondents}

The demographic characteristics of the respondents are summarised in Table 1. The majority of the respondents were male $(89.7 \%)$. Most respondents either fell in the 21-30 $(31.8 \%)$ age category or $31-40(23.8 \%)$ category, while the least were aged 15-20 (3.4\%). Based on the level of education, the majority of the respondents (47.5\%) have complete secondary school education while only $3.4 \%$ respondents reported having university degrees or equivalent qualifications. Family sizes are large with the majority $(34.5 \%)$ reporting having seven or more household members.

Table 1. Distribution of respondents by demographic characteristics.

\begin{tabular}{|c|c|c|c|}
\hline $\begin{array}{l}\text { Demographic } \\
\text { Characteristics }\end{array}$ & Responses & Frequency & $\begin{array}{l}\text { Percentage } \\
(\%)\end{array}$ \\
\hline \multirow[t]{3}{*}{ Gender } & Female & 27 & 10.3 \\
\hline & Male & 234 & 89.7 \\
\hline & Total & 261 & 100.0 \\
\hline \multirow[t]{7}{*}{ Age } & $15-20$ & 9 & 3.4 \\
\hline & $21-30$ & 83 & 31.8 \\
\hline & $31-40$ & 62 & 23.8 \\
\hline & $41-50$ & 57 & 21.8 \\
\hline & $51-60$ & 37 & 14.2 \\
\hline & Above 60 & 13 & 5.0 \\
\hline & Total & 261 & 100.0 \\
\hline \multirow[t]{8}{*}{ Education } & No formal schooling & 16 & 6.1 \\
\hline & Primary school dropouts & 10 & 3.8 \\
\hline & Complete Primary school & 47 & 18.0 \\
\hline & $\begin{array}{l}\text { Secondary school } \\
\text { dropouts }\end{array}$ & 13 & 5.0 \\
\hline & $\begin{array}{l}\text { Complete secondary } \\
\text { school }\end{array}$ & 124 & 47.5 \\
\hline & Post-secondary & 42 & 16.1 \\
\hline & Degree and above & 9 & 3.4 \\
\hline & Total & 261 & 100.0 \\
\hline \multirow[t]{6}{*}{ Household size } & None & 14 & 5.4 \\
\hline & One or two & 33 & 12.6 \\
\hline & Three or four & 44 & 16.9 \\
\hline & Five or six & 80 & 30.7 \\
\hline & Above seven & 90 & 34.5 \\
\hline & Total & 261 & 100.0 \\
\hline
\end{tabular}

\subsection{Respondents' Knowledge on Malaria}

Respondents answered a number of questions to gauge their knowledge about malaria ranging from basic information about malaria to sources of information, signs and symptoms as well as transmission and prevention of malaria. The majority $(97.7 \%)$ of the respondents have heard about malaria before while $96.9 \%$ of respondents correctly associated mosquito as malaria vector as shown in Table 2. Sources of information varied amongst respondents. Radio is the main source $(93.1 \%)$, followed by the clinic $(71.26 \%)$ and co-workers $(49.81 \%)$ were the most common sources of information about malaria as indicated in Table 3. Other common sources include family members $(45.98 \%)$, neighbours $(32.57 \%)$, and church/mosque $(29.5 \%)$.

Table 2. Knowledge about malaria.

\begin{tabular}{lll}
\hline Question & $\begin{array}{l}\text { Frequency } \\
\text { (correct } \\
\text { responses) }\end{array}$ & $\begin{array}{l}\text { Percentage } \\
\text { (\%) }\end{array}$ \\
\hline $\begin{array}{l}\text { Have you ever heard about malaria? } \\
\begin{array}{l}\text { Which vector can transmit malaria to } \\
\text { humans? }\end{array}\end{array}$ & 255 & 97.7 \\
$\begin{array}{l}\text { Malaria can be transmitted to humans by? } \\
\text { Do you think malaria can kill if it is not } \\
\text { treated? }\end{array}$ & 251 & 96.9 \\
\hline
\end{tabular}

Table 3. Respondents' sources of information about malaria.

\begin{tabular}{lll}
\hline Responses & Frequency & Percentage (\%) \\
\hline Family member & 120 & 45.98 \\
Neighbour & 85 & 32.57 \\
Radio & 243 & 93.10 \\
Television & 56 & 21.46 \\
Newspapers & 24 & 9.20 \\
Church/Mosque & 77 & 29.50 \\
Clinic & 186 & 71.26 \\
Co-worker/Colleague & 130 & 49.81 \\
I don't Know & 11 & 4.21 \\
Other & 49 & 18.77 \\
\hline
\end{tabular}

Note: Frequencies and Percentages add up to more than 261 and $100 \%$ respectively due to multiple responses.

In addition, the guards responses to questions on malaria signs and symptoms coupled with malaria prevention methods practised were summarised in Table 4 and Table 5. Both questions permitted respondents to select multiple answers from a range of answers and most respondents $(98.85 \%)$ associated malaria with high temperature/fever.

Table 4. Respondents' knowledge on signs and symptoms of malaria.

\begin{tabular}{lll}
\hline Responses & Frequency & Percentage (\%) \\
\hline High temperature/Fever & 258 & 98.85 \\
Vomiting & 15 & 5.75 \\
Headache & 220 & 84.29 \\
Itching & 5 & 1.92 \\
Chills & 8 & 3.07 \\
Loss of energy & 35 & 13.41 \\
Sweating & 20 & 7.66 \\
Body pains & 128 & 49.04 \\
Loss of appetite & 140 & 53.64 \\
Dizziness & 25 & 9.58 \\
I don't Know & 4 & 1.53 \\
\hline
\end{tabular}

Note: Frequencies and Percentages add up to more than 261 and $100 \%$ respectively due to multiple responses.

Table 5. Malaria prevention methods practised by the respondents.

\begin{tabular}{lll}
\hline Malaria prevention methods & Frequency & Percentage (\%) \\
\hline When Off-duty Insecticide-treated nets & 180 & 68.97 \\
(ITNs) & 48 & 18.39 \\
Repellents & 129 & 49.43 \\
Mosquito coil & 57 & 21.84 \\
Spraying Insecticides & 240 & 91.95 \\
Wearing long-sleeved shirts & & \\
\hline
\end{tabular}




\begin{tabular}{lll}
\hline Malaria prevention methods & Frequency & Percentage (\%) \\
\hline Making fire and smoke & 17 & 6.51 \\
Trimming of bushes & 193 & 73.95 \\
Others & 38 & 14.56 \\
When On-duty Insecticide-treated nets & 114 & 43.68 \\
(ITNs) & 25 & 9.58 \\
Repellents & 153 & 58.62 \\
Mosquito coil & 31 & 11.88 \\
Spraying Insecticides & 255 & 97.70 \\
Wearing long-sleeved shirts & 12 & 4.60 \\
Making fire and smoke & 261 & 100.00 \\
Trimming of bushes & 21 & 8.05 \\
Others & &
\end{tabular}

Note: Frequencies and Percentages add up to more than 261 and $100 \%$ respectively due to multiple responses.

\subsection{Respondents' Overall Knowledge, Attitude and Practices Score Towards Malaria Prevention and Control}

There were 253 (96.94\%) respondents with a high knowledge score about malaria, $4(1.53 \%)$ of them had medium and low knowledge score about malaria each. The highest and lowest score of 7 points and 2 points was recorded respectively amongst the guards. The mean knowledge score for all respondents was 5.332 out of a possible 7 points as highlighted in the Table 6 .

Table 6. Distribution of knowledge score about malaria amongst guards.

\begin{tabular}{lll}
\hline Level of Score & Frequency & Percentage (\%) \\
\hline High (score 7) & 253 & 96.94 \\
Medium (score 5-6) & 4 & 1.53 \\
Low (0-4) & 4 & 1.53 \\
Total & 261 & $100.00 \%$ \\
\hline
\end{tabular}

Minimum Score=2; Maximum Score=7; Mean=5.332

An overall attitude score was determined for each respondent by adding up the scores across the 13 attitude questions. There were $201(78 \%)$ of respondents with a positive attitude, $31(12 \%)$ of them had a neutral attitude, while $26(10 \%)$ had a negative attitude towards malaria prevention and control as summarised in Table 7. The mean attitude score for all respondents was 24.89 out of a possible 39 points.

Table 7. Distribution of malaria attitudes score of guards towards malaria prevention and control.

\begin{tabular}{lll}
\hline Level of Score & Frequency & Percentage (\%) \\
\hline Positive (score $>33)$ & 204 & $78 \%$ \\
Neutral $($ score $25-32)$ & 31 & $12 \%$ \\
Negative $(<24)$ & 26 & $10 \%$ \\
Total & 261 & $100 \%$ \\
\hline
\end{tabular}

Minimum Score $=0$; Maximum Score $=39$; Mean Score $=24.89$

There were $192(74 \%)$ of respondents with good practices score, $50(19 \%)$ of them had fair practices score, while 19 $(7 \%)$ had poor practices score towards malaria prevention and control. The highest and lowest score of 37 and 0 points was recorded respectively amongst the guards in relation to malaria practices score. The mean practices score for all respondents was 14.57 out of a possible 22 points. Table 8 summarises the distribution of malaria practices score across all respondents.

Table 8. Distribution of practices score by guards towards malaria prevention and control.

\begin{tabular}{lll}
\hline Level of Score & Frequency & Percentage (\%) \\
\hline Good (score $>16)$ & 192 & $74 \%$ \\
Fair $($ score $10-15)$ & 50 & $19 \%$ \\
Poor $(<9)$ & 19 & $7 \%$ \\
Total & 261 & $100 \%$ \\
\hline
\end{tabular}

Minimum Score=0; Maximum Score=18; Mean=14.57

\subsection{Comparison of Malaria Practices Across Independent Variables}

To explore association between demographics characteristics and various variables, different characteristics were categorized into groups. Related studies on malaria (Masangwi et al., 2012; Thanabouasy, Pumpaibool and Kanchanakhan. 2009) have used similar grouping principles to determine associations. In this study, respondent age was categorized into 3 groups- youth were aged between 15 and 30 , adults were aged between 31 and 50, while mature respondents were taken as those aged 51 years or more. Proportion of each category are summarised in Table 9.

Table 9. Distribution of respondents by age.

\begin{tabular}{lll}
\hline Age (yr) & Frequency & Percentage (\%) \\
\hline Youth (15-30) & 92 & $35.2 \%$ \\
Adult (31-50) & 119 & $45.6 \%$ \\
Elderly (51+) & 50 & $19.2 \%$ \\
Total & 261 & $100.0 \%$ \\
\hline
\end{tabular}

The comparison of malaria practice scores to demographic characteristics, knowledge about malaria and attitudes towards malaria across all respondents are summarised in Table 10,11 and 12 respectively.

Comparing malaria practice scores to different demographic characteristics (gender, age, and educational level) using the Chi-Square test indicated that there was statistically significant association between malaria practices and the respondent's age ( $\mathrm{p}$-value $=0.022)$ as well as between malaria practices and the respondent's gender ( $p$ value $=0.002$ ) and again malaria practice significantly associate with the level of education ( $p$-value $=0.006$ ) as shown in Table 10.

Table 11 shows the comparison of malaria practice scores to malaria knowledge scores. Chi-Square test indicated that there was statistically significant association between respondent's knowledge about malaria and their practices towards malaria $(\mathrm{p}=0.008)$. This finding implies that the more informed the respondents about malaria ethics, the more he/she puts it into practice consciously.

Comparing malaria practice scores to malaria attitude scores using the Chi-Square test indicated that there is statistically significant association between respondent's attitude towards malaria and their practices towards malaria $(\mathrm{p}=0.020)$ as revealed in Table 12. 
Table 10. Association between age, gender, education and malaria practices.

\begin{tabular}{|c|c|c|c|c|c|c|}
\hline Factor & Category & Good practice & Fair practice & Poor practice & Total & p-value \\
\hline \multirow[t]{3}{*}{ Age } & Youth & 102 & 36 & 16 & 154 & \\
\hline & Adult & 79 & 12 & 03 & 94 & 0.022 \\
\hline & Elderly & 11 & 02 & 00 & 13 & \\
\hline Total & & 192 & 50 & 19 & 261 & \\
\hline \multirow[t]{2}{*}{ Gender } & Male & 134 & 55 & 45 & 234 & 0.002 \\
\hline & Female & 25 & 01 & 01 & 27 & \\
\hline Total & & 181 & 63 & 17 & 261 & \\
\hline \multirow{2}{*}{ Educational Level } & Schooled halfway & 12 & 08 & 03 & 23 & 0.006 \\
\hline & Schooled & 91 & 107 & 24 & 222 & \\
\hline Total & & 111 & 120 & 30 & 261 & \\
\hline
\end{tabular}

Table 11. Association between malaria practices and malaria knowledge.

\begin{tabular}{lllll}
\hline \multirow{2}{*}{ Malaria practice } & \multicolumn{4}{l}{ Malaria Knowledge } \\
\cline { 2 - 5 } & High & Medium & Low & Total \\
\hline Good practice & 178 & 1 & 0 & 179 \\
Fair practice & 58 & 0 & 3 & 61 \\
Poor practice & 19 & 1 & 1 & 21 \\
Total & 255 & 2 & 4 & 261 \\
\hline
\end{tabular}

$\mathrm{X}^{2}=13.888 ; \mathrm{p}=0.008$

Table 12. Association between malaria practices and attitude.

\begin{tabular}{lllll}
\hline \multirow{2}{*}{ Malaria practice } & \multicolumn{4}{l}{ Malaria Attitude } \\
\cline { 2 - 5 } & Positive & Neutral & Negative & Total \\
\hline Good practice & 174 & 6 & 1 & 181 \\
Fair practice & 58 & 3 & 2 & 63 \\
Poor practice & 14 & 1 & 2 & 17 \\
Total & 246 & 10 & 5 & 261 \\
\hline
\end{tabular}

$\mathrm{X}^{2}=11.695 ; \mathrm{p}=0.020$

\section{Discussion}

In relation to knowledge about malaria, majority of respondents correctly associated mosquitos with malaria transmission (96.9\%) and acknowledged that malaria kills if it is not treated $(93.1 \%)$. The outcome from this study have been supported by other studies affirming that improved community knowledge of malaria and its source of transmission promote preventive and personal protection practices amongst the affected community which gives an opportunity for any malaria prevention and control intervention to utilise $[17,18]$. An overall knowledge score was calculated by adding up the scores for each respondent across the scaled questions. There were $96.94 \%$ of respondents with high knowledge about malaria, $1.53 \%$ of them had medium and low knowledge about malaria each, indicating that the distribution of knowledge about malaria across all respondents is highly significant. Most respondents associated malaria with high temperature/fever which was in agreement with other studies [7, 19]. This finding agrees with the submissions of Adegun et al. (2011) and, Oyewole and Ibidapo (2007) [20, 21] who showed that the general knowledge about malaria prevention was good but varies with the conclusion of Adebayo et al. (2015) and, Onyeaso and Fawole (2007) [14, 22] who reported poor knowledge of malaria preventive strategies.

The majority $(60.2 \%)$ of the respondents stated they would seek treatment within 24 hours of onset of malaria symptoms while $30.8 \%$ seek treatment between 2-3days implying that majority of the respondents seek for treatment within 1-3days after suspecting symptoms. This is in line with the Abuja summit on malaria, which says, "at least $60 \%$ of those suffering from malaria should seek treatment within 24 hours of the onset of symptoms" [23]. However, this is far below the percentage of another study in Swaziland [24] which reported that $90 \%$ of respondents would seek treatment within 24 hours of seeing the first symptoms of malaria. This indicates that there is still sufficient room for improvement in Nigeria's efforts to encourage positive malaria treatment seeking behaviours.

Attitude, "a compound of affect, cognition and behaviour" is an important component in malaria control although it has not been adequately considered in the design of interventions such as health education promotion messages, hindering sustainable control [7]. On the whole, respondents do recognize the threat posed by malaria as most (94.5\%) agreed with the statement that "I think that malaria is a serious and life-threatening disease" while $90.8 \%$ agreed that their present job increases their risk level of getting malaria while self-medication is on the low side as can be inferred from the respondents responses $(35.6 \%)$. It therefore implies that the buying of anti-malaria drugs from the pharmacy is based on Doctor's prescription being that one cannot recover spontaneously from the disease except when placed on medication as indicated by $79.7 \%$ of the respondents. The majority of the respondents $(78 \%)$ had positive attitude towards malaria prevention and control.

In relation to practices, sleeping under bed nets was the most prevalent method of malaria prevention and control. On a general look, the majority of the respondents owns and uses the bed net. Given the prominent role already played by bed nets in the fight against malaria, control programmes can build on this opportunity to fight malaria. Even though, it is fine to have mass campaigns that distribute free bed nets, but care must be taken to teach people how to effectively use them and create ownership or pride that prevents misuse because bed nets were free hand-outs. 


\section{Conclusion}

This study has shed light on the level of understanding about knowledge, attitudes and practices on malaria prevention and control among private security guards within Kaduna metropolis, Kaduna state-Nigeria. It has generated information useful to health education promoters and policy makers for guidance towards malaria elimination campaigns. Data from this study shows the respondents have high knowledge, attitude and practice scores against malaria which further calls for continuous and relentless control measures with enlightenment campaigns to further educate people on malaria, because it is entirely preventable and curable.

\section{References}

[1] WHO. (2006). Malaria vector control and personal protection: report of a WHO study group.

[2] Krief, S., Escalante, A. A., Pacheco, M. A., Mugisha, L., André, C., Halbwax, M., and Cornejo, O. E. (2010). On the diversity of malaria parasites in African apes and the origin of Plasmodium falciparum from Bonobos. PLoS Pathogen, 6 (2).

[3] Nonstrand, V. (1978). Malaria in Scientific Encyclopedia (6th ed.). Van Nonstrand Reinhold Company, New York, pp. 18121813.

[4] Miller, S. A. and Marley, J. P. (1999). Zoology 4th Edition. WMC Brown Publishers, Debuque Lowa Melbourne, Australia. pp. 251-253.

[5] WHO. (2015). World Malaria Report 2015. World Health Organization, Geneva, Switzerland.

[6] WHO. (2014). WHO Fact sheet. Available from: www.who.int/mediacentre/factsheets/fs094/en/.

[7] Shimaponda-Mataa, N. M., Tembo-Mwase, E., Gebreslasie, M., and Mukaratirwa, S. (2016). Knowledge, attitudes and practices in the control and prevention of malaria in four endemic provinces of Zambia. Southern African Journal of Infectious Diseases, 1 (1): 1-11.

[8] Karunamoorthi, K., \& Kumera, A. (2010). Knowledge and health seeking behavior for malaria among the local inhabitants in an endemic area of Ethiopia: implications for control. Health, 2 (06): 575.

[9] Chirebvu, E., Chimbari, M. J., and Ngwenya, B. N. (2013). Knowledge and practices on malaria in Tubu village, in a malaria-endemic area in northern Botswana: implications for interventions. Malaria World Journal, 4 (15): 1-9.

[10] Ahorlu, C. K., Dunyo, S. K., Afari, E. A., Koram, K. A., and Nkrumah, F. K. (1997). Malaria-related beliefs and behaviour in Southern Ghana: Implications for treatment, prevention and control. Tropical Medicine \& International Health, 2 (5): 488-499.

[11] Laver, S. M., Wetzels, J., and Behrens, R. H. (2001). Knowledge of malaria, risk perception, and compliance with prophylaxis and personal and environmental preventive measures in travelers exiting Zimbabwe from Harare and Victoria Falls International airport. Journal of Travel
Medicine, 8 (6): 298-303.

[12] Alaii, J. A., Van Den Borne, H. W., Kachur, S. P., Shelley, K., Mwenesi, H., Vulule, J. M.,... and Phillips-Howard, P. A. (2003). Community reactions to the introduction of permethrin-treated bed nets for malaria control during a randomized controlled trial in western Kenya. The American Journal of Tropical Medicine and Hygiene, 684 suppl): 128136.

[13] Obol, J., David Lagoro, K., and Christopher Garimoi, O. (2011). Knowledge and Misconceptions about Malaria among Pregnant Women in a Post-Conflict Internally Displaced Persons' Camps in Gulu District, Northern Uganda. Malaria research and treatment, 2011: 1-7.

[14] Adebayo, A. M., Akinyemi, O. O., and Cadmus, E. O. (2015). Knowledge of malaria prevention among pregnant women and female caregivers of under-five children in rural southwest Nigeria. PeerJ, 3: e792.

[15] Mohammed, M., Vantsawa, P. A, Abdullahi, U. Y. and Muktar, M. D. (2015). Nutritional Status and Prevalence of Intestinal Schistosomiasis among Al-majiri Population in Kawo District of Kaduna Metropolis, Kaduna State-Nigeria. Journal of Bacteriology and Parasitology, 6: 237-242.

[16] Umaru, M. L., and Uyaiabasi, G. N. (2015). Prevalence of Malaria in Patients Attending the General Hospital Makarfi, Makarfi Kaduna-State, North-Western Nigeria. American Journal of Infectious Diseases and Microbiology, 3 (1): 1-5.

[17] Ahorlu, C. K., Koram, K. A., Arholu, C., De Savigny, D. and Weiss, M. G. (2006). Sociocultural determinants of treatment delay for childhood Malaria in southern Ghana. Tropical Medicine and International Health, 11 (7): 24-32.

[18] Tatem, A. J., and Smith, D. L. (2010). International population movements and regional Plasmodium falciparum malaria elimination strategies. Proceedings of the National Academy of Sciences, 107 (27): 1222-1227.

[19] Forero, D. A., Chaparro, P. E., Vallejo, A. F., Benavides, Y., Gutiérrez, J. B., Arévalo-Herrera, M., and Herrera, S. (2014). Knowledge, attitudes and practices of malaria in Colombia. Malaria Journal, 13 (1): 1.

[20] Adegun Joel, A., Adegboyega, J. A., and Awosusi Ajoke, O. (2011). Knowledge and the preventive strategies of malaria among migrant farmers in Ado-Ekiti Local Government Area of Ekiti State, Nigeria. American Journal of Scientific and Industrial Research, 2: 883-889.

[21] Oyewole, I. O., and Ibidapo, A. C. (2007). Attitudes to malaria, prevention, treatment and management strategies associated with the prevalence of malaria in a Nigerian urban center. African Journal of Biotechnology, 6: 2424-2427.

[22] Onyeaso, N. C., and Fawole, A. O. (2007). Perception and practice of malaria prophylaxis in pregnancy among health care providers in Ibadan. African Journal of Reproductive Health, 11 (2), 69-78.

[23] WHO. (2000). World Health Organization. The Abuja Declaration on Roll Back Malaria in Africa. African Heads of States and Governments.

[24] Hlongwana, K. W., Mabaso, M. L., Kunene, S., Govender, D., and Maharaj, R. (2009). Community knowledge, attitudes and practices (KAP) on malaria in Swaziland: a country earmarked for malaria elimination. Malaria Journal, 8 (1): 1. 